\title{
Fatigue behaviour of natural rubber in marine environment: comparison between air and sea water
}

\author{
Pierre-Yves Le Gac ${ }^{a,{ }^{*}}$, Mael Arhant ${ }^{a}$, Peter Davies ${ }^{a}$, Alan Muhr ${ }^{b}$
}

\author{
a IFREMER, Marine Structures Laboratory, Centre Bretagne, France \\ ${ }^{b}$ Tun Abdul Razak Research Centre (TARRC), Hertford, UK \\ *: Corresponding author : Pierre-Yves Le Gac, tel.: +33298224845 ; email address : pierre.yves.le.gac@ifremer.fr
}

\begin{abstract}
:
Natural rubber has been successfully used in a marine environment for many years. However, most applications involve low dynamic loadings. Due to the emergence of marine energy recovery, wave and tidal energy converters are being developed. In some such devices, rubbers are subjected to severe cyclic loadings, very different from their previous use in air or water. Such rubbers must therefore be qualified for long-term use in sea water with high fatigue loading. This paper presents a study using a new fatigue machine that allows the fatigue behaviour of rubber in sea water to be compared to that in air. The results show that the benefit of non-relaxing conditions on fatigue lifetime of natural rubber can be significantly reduced when it is used in sea water, observed in particular for a ratio of minimum to maximum strain of $R=0.2$. In order to understand this new result, the effects of both antioxidant and of minimum strain during the fatigue cycle were investigated. The effect of antioxidant was found to be the same in sea water and air, i.e. an increase of the stabiliser level leads to an increase in fatigue life, so It appears that antioxidant leaching is not the origin of the reduction of fatigue life in sea water. It was noted that this reduction of number of cycles to failure does not occur when natural rubber is used in sea water in fully relaxing cycles, suggesting that strain induced crystallisation, responsible for the beneficial effect of non-relaxing cycles on fatigue resistance, might be adversely influenced by sea-water at a ratio $R$ of minimum to maximum strain equal to 0.2 .
\end{abstract}

\section{Highlights}

- The paper presents original fatigue results for natural rubber in sea water. An important influence of sea water testing compared to air is revealed. $\$$ The influence of stabilizers is examined to provide an explanation for differences.

Keywords : Natural Rubber ; Water ; Fatigue ; Stabilisation 
1.Introduction:

World energy demand is steadily increasing, and although recent shale oil and gas discoveries have increased reserves these are not unlimited. Sooner or later alternative sources of energy will be needed, and renewable energy sources are of particular interest. These are defined as those coming from any resource which is naturally replenished on a human timescale. Because the oceans represent more than $70 \%$ of the earth's surface there has been a particular interest in marine renewable energy, and many new concepts of energy converters from waves, tidal or temperature gradient are now available. In order to ensure economic viability of such energy converters, reduced maintenance and long term durability of these structures in this severe environment is of major interest.

Durability of structures in a marine environment depends critically on both design and material. Polymers and composites are widely used at sea, driven by the desirability of weight reduction and avoidance of metal corrosion. Durability of polymers and composites in sea water has been widely studied in the past mainly for subsea oil and gas extraction [1 - 4] and for military purposes [5]. However, for most of these applications mechanical loading is usually either static or, if dynamic, with low stress or strain amplitudes. This is no longer the case when considering marine energy converters, particularly wave energy converters [6 - 8], which need to undergo large movements in order to operate. In order to manage the fatigue issue, material selection tends to the use of rubbers when possible, and natural rubber in particular as it has unsurpassed fatigue resistance in air because of its capacity to crystallize at high strain. 1 $[9-12]$.

Natural rubbers are already used in marine structures and show good long term behavior. In fact, if the material is well formulated water absorption is low (about 1\%) and does not significantly affect quasi static mechanical properties [13-16]. It is worth noting however, that rubbers are complex formulations and the choice of additives and fillers is very important when considering their long term behavior [17-18]. But the main outstanding question is about the fatigue behavior of such materials in a marine environment and in particular, does the good fatigue behavior of NR in air change when immersed in sea water. Mott and Roland [19] studied the effect of ageing of NR in sea water compared to ageing in air on properties, including fatigue life, measured subsequently in air and concluded that the behavior is the same, and due to oxidation. However, they did not investigate fatigue behaviour of immersed rubber. Fatigue of 
natural rubber immersed in distilled water has been performed by Lake [20]; the results were not fully resolved for unprotected rubber (i.e. without stabilization), water immersion led to an improvement of fatigue life for low strain, probably because of the lack of ozone attack underwater. For protected samples no difference between water and air was observed. However, in his study a large water absorption was observed (up to $10 \%$ ), because the osmotic balance was tipped in favour of water absorption, there being no solutes in the water, and the rubber, being unfilled, had a low elastic modulus. The absorbed water formed blisters in the rubber, since it is very sparingly soluble in polyisoprene, but the blisters evidently are not effective fatigue initiation sites. More recently Selden [21] studied the effect of immersion on crack propagation in NR and concluded that there was a small effect, especially at low crack growth rate.

Based on data from the literature it would thus be expected that immersion of natural rubber in sea water will not greatly affect its fatigue lifetime, but more evidence is needed, covering materials and duty cycles more relevant to the conditions proposed for wave energy converters; this is the main objective of the current study.

To study the effect of sea water immersion on fatigue behavior of natural rubber a new fatigue rig was developed and will be presented in the first part of this paper. Testing conditions were chosen carefully in order to avoid self-heating of samples, to evaluate lifetime with a large number of samples per condition and to use a well-known rubber formulation. The second part of this paper will be devoted to the comparison of fatigue behavior in air and sea water under non-relaxing conditions. The third part will focus on the origins of the effects observed, and in particular the decrease in lifetime for rubber in sea water, together with an investigation into the effect of stabilizers in the formulation and the effect of the minimum strain. 


\section{Material and Methods :}

\subsection{Rubber formulation}

The materials used in this study are carbon black-filled natural rubbers whose compositions are shown in Table 1. The main characteristics of this compound, albeit with a different antidegradant or stabilizer system, can be found in the Engineering Data Sheets [22] In order to study the effect of antioxidants on the fatigue lifetime, three rubber have been formulated with different levels of stabilization called A, B and C.

\subsection{Water absorption}

The water absorption was determined from the weight evolution of square samples (50rent typemm) with a $2 \mathrm{~mm}$ thickness immersed in natural sea water renewed at $4 \mathrm{Lh}^{-}$ 1 at $25^{\circ} \mathrm{C}$. Mass gain was followed by periodic weighing on a Sartorius LA $310 \mathrm{~S}$ balance (precision $0.1 \mathrm{mg}$ ). Samples were removed from the ageing containers and wiped with paper towels to dry the surfaces before weighing. The mass change (M) of each sample at time $t$ is expressed as a percentage as:

$$
M(t)=\frac{m(t)-m_{o}}{m_{o}} \cdot 100
$$

where $m(t)$ is sample mass at time $t$ and $m_{0}$ is the dry sample mass (the initial weight of material prior to water exposure) before immersion. For each condition (temperature, pressure and thickness), 3 samples were weighed to ensure the reliability of the measurement.

\subsection{Fatigue tests}

\subsubsection{Samples}

Fatigue tests were performed using dumbbell samples with a thickness of $2 \mathrm{~mm}$ and a type 2 shape according to the ISO Standard 37:2011 [23]. There were three main reasons for this choice; the first is to avoid self-heating in the samples, in order to use 
the same thermal conditions in both air and sea water, so the use of thick diabolo specimens was not possible here. Secondly, the use of test-pieces bonded to end fixtures was thought to risk the complication of bond failure (eg underbond corrosion) limiting the lifetime. Finally, total break of type 2 dumbbells is a convenient end of life criterion for monitoring in these tests [24].

\subsubsection{Fatigue machine}

Experiments have been conducted on a fatigue test facility developed at Ifremer in which seven replicate specimens can be tested. It is composed of an electrical displacement controlled piston PRA3810S from Parker piloted by a computer. Maximum force and frequency available during a cycle are respectively $1860 \mathrm{~N}$ and $7 \mathrm{~Hz}$. Figure 1 shows one of the machines developed for this study.

The main aim of the study is to see whether or not sea water has an influence on the fatigue life of rubber. Tests were performed in tanks of natural sea water renewed at $4 \mathrm{~L} / \mathrm{h}$ and controlled at $25^{\circ} \mathrm{C}$ as for the water absorption tests. As working either in air or in sea water can result in different thermal conditions, the temperature was controlled at $25^{\circ} \mathrm{C}$ for both. It has been suggested that oxidation is a phenomenon which can cause early rupture in rubber [ 25 - 27]. Here, in order to ensure that there is a maximum of oxygen, air bubbles were introduced through a water pump in the tank. The fatigue tests were conducted by prescribing a sinusoidal displacement. In order to avoid corrosion problems, mountings have been built in titanium.

\subsubsection{Fatigue conditions}

In order to avoid any self heating of the specimens each fatigue test in this study was performed at $2 \mathrm{~Hz}$. This choice was based on results from a preliminary study in which an Infra Red camera was used to measure surface temperature changes for different cycling frequencies (Figure 2), and ensures that the temperature rise was below $5^{\circ} \mathrm{C}$ for fatigue in air.

The end of fatigue life criterion was chosen to be the complete break of the sample. As seven specimens were tested with the same piston, in order to detect the rupture of each specimen, pictures were taken at regular time intervals using a 
Logitech $^{\text {TM }}$ C310 digital camera placed next to each machine. For each condition, at least 7 samples were tested and the mean and standard deviation of the log(fatigue life) values calculated. Tests were performed under displacement control. In addition to the effect of the medium, the influence of the R-ratio (minimum strain/maximum strain) and of stabilizing additives has been studied. Log (Fatigue life) results were fitted with an affine equation, and fit parameters are reported directly in the Figures with a linear correlation coefficient $\mathrm{R}^{2}$.

Unless otherwise stated, all specimens were stabilized by a conditioning sequence of 1000 cycles at the same displacement as the fatigue test in order to take into account material elongation that occurs mostly at the beginning of the test $[27,28]$. True local strain in the narrow section of the dumbbells was measured for each specific grip-to-grip displacement after these 1000 cycles using digital image correlation with a fast acquisition camera coupled with Aramis ${ }^{\mathrm{TM}}$ software. 


\section{Results and discussion}

\subsection{Water absorption}

When rubbers are immersed, water diffuses into the material and can lead to reversible or irreversible degradation [29 - 31]. In the case of natural rubber, with a suitable formulation, water absorption is expected to be low. For more polar rubbers, or rubbers incorporating hydrophilic or ionic fillers, a large amount of water may be absorbed ("swelling") leading to modification of mechanical properties [32]. Here, the water absorption in the rubber was about $1 \%$ by weight when the material was immersed in natural sea water at $25^{\circ} \mathrm{C}$ (Figure 3 ). This result suggests that in this study any change in fatigue life observed when the rubber is immersed in sea water cannot be attributed to water absorption in the NR.

\subsection{Fatigue Life in non relaxing conditions $(\mathrm{R}=0.2)$}

Natural rubber undergoes strain induced crystallization, greatly enhancing its strength, especially when used in non relaxing fatigue conditions, because the crystallinity does not completely melt during the unloading part of the cycle unless the minimum strain is very low $[13,33-34]$. This feature is often exploited to increase the fatigue life of the material. In order to study the effect of immersion in sea water on fatigue behavior of $\mathrm{NR}$, a comparison of fatigue life in air and sea water with a ratio $\mathrm{R}$ of minimum to maximum tensile strain of 0.2 was performed; results are shown in Figure 4. A clear decrease of the fatigue life of NR is observed when tests are performed in sea water compared to results in air. In order to understand the origin of this loss, particular attention has been paid to the effect of stabilizers.

Error bars in this and subsequent plots show the standard deviation of the logarithm of number of cycles to failure using 7 replicates for each test condition.

\subsection{Effect of stabilization on fatigue life}

It is well known that fatigue life of natural rubber is affected by the efficiency of the stabilizing additives included in the formulation. These additives are of many different 
types and exhibit at least one of three distinct effects (i) mitigation of thermallyactivated oxidation, achieved by "antioxidants" (ii) mitigation of mechano-oxidative crack growth - achieved by "antiflex-cracking antioxidants" (iii) mitigation of ozone attack, achieved by "antiozonants". [26,27]. In fact for a specific stabilization system, the higher the concentration of stabilizers in the rubber the longer will be the fatigue lifetime (up to a certain limit). So two main questions have to be considered here, first does this positive effect of stabilization occur when rubbers are used in sea water? And second, could leaching of these antioxidants from the rubber to sea water explain the observed loss in fatigue life?

The effect of stabilization content in the rubber on fatigue life when immersed in sea water is considered here by tests on three formulations which vary only by the amounts of anti-oxidants they contain. The results are shown in Figure 5.

Figure 5 clearly shows that even if rubber is immersed in sea water a large improvement in fatigue life can be obtained by increasing the level of stabilization, this is the same behavior as in air. Because fatigue life of NR depends on the level of stabilization and the fact that antioxidant might be leached in sea water, the fatigue behavior of a non stabilized natural rubber was then compared in both air and sea water in non relaxing conditions. Results are plotted in figure 6.

In the same way as for the stabilized materials, a significant decrease of fatigue life is observed when samples are tested in sea water compared to air, even when there is no stabilization in the formulation. These results clearly show that the reduction in fatigue lifetime in sea water cannot be attributed to stabilizer leaching. These results clearly show that the reduction in fatigue lifetime in sea water cannot be attributed to stabilizer leaching if there is not a significant effect of natural antioxidant in sulphur-vulcanized NR. Furthermore it appears that the relative loss in terms of cycles to failure is similar for both materials meaning that the relative drop is independent of the anti-oxidant level. The influence of R-ratio on fatigue life will now be considered, in order to understand the origin of this loss. 


\subsection{Fatigue Life under relaxing conditions $(\mathrm{R}=0)$}

When tested under relaxing conditions with complete unloading, the induced crystallization in natural rubber is removed every cycle, so that its benefit is reduced and a lower fatigue life is expected. Here the effect of water immersion is now considered on EDS 14 C, i.e. with antioxidant but with an R-ratio equal to 0 (after the conditioning sequence). Results are presented in figure 7 , it appears that there is now no difference in terms of number of cycles to failure between samples tested in air or in sea water.

The fact that there is no decrease of the fatigue life in sea water compared to air when NR is tested under fully relaxing conditions, Figure 7, suggests that the observed loss under non relaxing conditions (Figures 3 and 5) could be related to a reduction in the effectiveness of strain induced crystallization to enhance fatigue resistance. The presence of water could affect either the crystallization process itself or the stress relaxation mechanism [13] and so modify the minimal stress level that is directly linked to SIC [33 -38]. These hypotheses will be considered in a future study.

Results from tests at different R-ratios, Figure 8, show a clear increase of fatigue life of natural rubber tested in sea water when the $\mathrm{R}$ factor is increased, in qualitative accord with results in air. This indicates that even if immersion in sea water leads to a reduction of the fatigue life of NR in non-relaxing conditions, this kind of material could still be used for devices with high cyclic loading if it is possible to design for a higher ratio $R$. 


\section{Conclusions}

The fatigue behavior of natural rubber in sea water has been considered in this study. First a new fatigue device has been developed in order to be able to compare fatigue life time in air and sea water under appropriate conditions, i.e. without large self-heating of samples, with the same temperature, and the same oxygen content.

When tested in sea water in non relaxing conditions (here $\mathrm{R}=0.2$ ) a significant decrease of the fatigue life of natural rubber is observed compared to air. This is an original result and implies that devices including rubber for use in a marine environment and subjected to large fatigue cycles cannot be designed reliably on the basis of fatigue results in air.

The exact origin of this decrease in fatigue life is not clear, however it has been shown that in sea water the relative effect of stabilizers is the same as in air, i.e. an increase of fatigue life is observed when the amount of stabilization is increased. Also, antioxidant leaching from the rubber to sea water appears not to be the reason for the decrease, since it occurs even for a material formulated without stabilizer. However, as there was no loss of fatigue lifetime observed when samples were tested under relaxing conditions the loss of fatigue life in sea water may be related to a reduced efficacy in water of the strain induced crystallization process. More work is required to clarify this.

\section{Acknowledgement}

The authors thank M Jacquet, N Lacotte and M Premel Cabic from Ifremer for their help in performing tests and the European Project MARINET for funding. 


\section{References}

[1] Davies, P., \& Rajapakse, Y. D. (Eds.). (2014). Durability of Composites in a Marine Environment. Springer.

[2] Kootsookos, A., \& Mouritz, A. P. (2004). Seawater durability of glass-and carbonpolymer composites. Composites Science and Technology, 64(10), 1503-1511.

[3] Jacques, B., Werth, M., Merdas, I., Thominette, F., \& Verdu, J. (2002). Hydrolytic ageing of polyamide 11. 1. Hydrolysis kinetics in water. Polymer, 43(24), 6439-6447.

[4] Le Duigou, A., Davies, P., \& Baley, C. (2009). Seawater ageing of flax/poly (lactic acid) biocomposites. Polymer Degradation and Stability, 94(7), 1151-1162.

[5] Roland, C. M. (2009). Naval and Space Applications of Rubber, Chapter 5 in Rubber

Technologists Handbook, Smithers Rapra Technology Limited, Shawbury UK. Volume 2, 159-188.

[6] Henderson, R. (2006). Design, simulation, and testing of a novel hydraulic power take-off system for the Pelamis wave energy converter. Renewable energy, 31(2), 271-283.

[7] Farley, F. J. M., Rainey, R. C. T., \& Chaplin, J. R. (2012). Rubber tubes in the sea.

Philosophical Transactions of the Royal Society A: Mathematical, Physical and Engineering Sciences, 370(1959), 381-402.

[8] Jean, P., Wattez, A., Ardoise, G., Melis, C., Van Kessel, R., Fourmon, A., ... \& Queau, J. P. (2012, April). Standing wave tube electro active polymer wave energy converter. In SPIE Smart Structures and Materials+ Nondestructive Evaluation and Health Monitoring (pp. 83400C-83400C). International Society for Optics and Photonics.

[9] Harbour, R. J., Fatemi, A., \& Mars, W. V. (2008). Fatigue life analysis and predictions for NR and SBR under variable amplitude and multiaxial loading conditions. International Journal of Fatigue, 30(7), 1231-1247.

[10] Beurrot-Borgarino, S., Huneau, B., Verron, E., \& Rublon, P. (2013). Straininduced crystallization of carbon black-filled natural rubber during fatigue measured by in situ synchrotron X-ray diffraction. International Journal of Fatigue, 47, 1-7.

[11] Le Saux, V., Marco, Y., Calloch, S., Doudard, C., \& Charrier, P. (2010). Fast evaluation of the fatigue lifetime of rubber-like materials based on a heat build-up protocol and micro-tomography measurements. International Journal of Fatigue, 32(10), 1582-1590.

[12] G. J. Lake and P. B. Lindley (1966) Mechanical Fatigue Limit for Rubber. Rubber Chemistry and Technology: May 1966, Vol. 39, No. 2, pp. 348-364.

[13] Derham C J 1972 Effect of moisture on the creep and stress relaxation of natural and synthetic general purpose rubbers . Proc Intl Rubber Conf, Brighton, Publ. IRI 1973

[14] Thomas, A. G., \& Muniandy, K. (1987). Absorption and desorption of water in rubbers. Polymer, 28(3), 408-415.

[15] Crank, J., Park, G. S., (editors) (1968). Diffusion in polymers, Academic Press, London $\&$ New York.

[16] Ab-Malek, K., \& Stevenson, A. (1986). The effect of 42 year immersion in sea-water on natural rubber. Journal of materials science, 21(1), 147-154.

[17] Fedors, R. F. (1980). Osmotic effects in water absorption by polymers. Polymer, 21(2), 207-212.

[18] Le Gac, P. Y., Roux, G., Davies, P., Fayolle, B., \& Verdu, J. (2014). Water clustering in polychloroprene. Polymer, Volume 55, Issue 12, 6 June 2014, Pages 2861-2866

[19] P. H. Mott and C. M. Roland (2001) Aging of Natural Rubber in Air and Seawater. Rubber Chemistry and Technology: March 2001, Vol. 74, No. 1, pp. 79-88. 
[20] Lake, G.J.and Pond, T.J., (1989), "Effects of aqueous environments on fatigue and elastic properties of rubber", Polymers in a Marine Environment, Marine Management Ltd, London, UK. pp 141-147

[21] Selden, R. (1998). The effect of water immersion on fatigue crack growth of two engineering rubbers. Journal of applied polymer science, 69(5), 941-946.

[22] TARRC (Tun Abdul Razak Research Centre) Engineering Data Sheet EDS14, published 1978, available from TARRC, Brickendonbury, Hertford, United Kingdom SG13 8NL.

[23] ISO 37:2011. Rubber, vulcanized or thermoplastic -- Determination of tensile stressstrain properties. ISO Standard, 2011

[24] Shangguan, W. B., Wang, X. L., Deng, J. X., Rakheja, S., Pan, X. Y., \& Yu, B. (2014). Experiment and modeling of uniaxial tension fatigue performances for filled natural rubbers. Materials \& Design, Volume 58, June 2014, Pages 65-73.

[25] G. J. Lake and P. B. Lindley (1966) Mechanical Fatigue Limit for Rubber. Rubber Chemistry and Technology: May 1966, Vol. 39, No. 2, pp. 348-364.

[26] A. N. Gent (1963) Some Chemical Effects in Fatigue Cracking of Vulcanized Rubbers. Rubber Chemistry and Technology: May 1963, Vol. 36, No. 2, pp. 399-406.

[27] Mars, W. V., \& Fatemi, A. (2002). A literature survey on fatigue analysis approaches for rubber. International Journal of Fatigue, 24(9), 949-961.

[28] Diani, J., Fayolle, B., \& Gilormini, P. (2009). A review on the Mullins effect. European Polymer Journal, 45(3), 601-612.

[29] Richaud, E., Gilormini, P., Coquillat, M., \& Verdu, J. (2014). Crosslink Density Changes during the Hydrolysis of Tridimensional Polyesters. Macromolecular Theory and Simulations. [30] Le Gac, P. Y., Choqueuse, D., \& Melot, D. (2013). Description and modeling of polyurethane hydrolysis used as thermal insulation in oil offshore conditions. Polymer Testing, 32(8), 1588-1593.

[31] Le Gac, P. Y., Le Saux, V., Paris, M., \& Marco, Y. (2012). Ageing mechanism and mechanical degradation behaviour of polychloroprene rubber in a marine environment: Comparison of accelerated ageing and long term exposure. Polymer Degradation and Stability, 97(3), 288-296.

[32] Chai, A. B., Andriyana, A., Verron, E., \& Johan, M. R. (2013). Mechanical characteristics of swollen elastomers under cyclic loading. Materials \& Design, 44, 566572.

[33] Brüning, K., Schneider, K., Roth, S. V., \& Heinrich, G. (2012). Kinetics of Straininduced crystallization in natural rubber studied by WAXD: Dynamic and impact tensile experiments. Macromolecules, 45(19), 7914-7919.

[34] Brüning, K., Schneider, K., Roth, S. V., \& Heinrich, G. (2013). Strain-induced crystallization around a crack tip in natural rubber under dynamic load. Polymer, 54(22), $6200-6205$.

[35] Huneau, B. (2011). Strain-induced crystallization of natural rubber: A review of X-ray diffraction investigations. Rubber chemistry and technology, 84(3), 425-452.

[36] Briggs, G. J., Edwards, D. C., \& Storey, E. B. (1963). Water Absorption of Elastomers. Rubber Chemistry and Technology, 36(3), 621-641. 
[37] Chenal, J. M., Gauthier, C., Chazeau, L., Guy, L., \& Bomal, Y. (2007). Parameters governing strain induced crystallization in filled natural rubber. Polymer, 48(23), 6893-6901. [38] Trabelsi, S., Albouy, P. A., \& Rault, J. (2002). Stress-induced crystallization around a crack tip in natural rubber. Macromolecules, 35(27), 10054-10061. 
List of table

Table 1 Formulations of the rubbers used in the study

List of figures

Figure 1 Testing machine developed at Ifremer

Figure 2 : Surface self-heating at EDS14 in air as function of frequency for a maximal strain of 2.5

Figure 3 : Water absorption in NR immersed in natural sea water at $25^{\circ} \mathrm{C}$

Figure 4 : Fatigue life of rubber in air and sea water under non-relaxing conditions $(R=0.2)$

Figure 5 : Effect of antioxidants level on the fatigue life of natural rubber in sea water $R=0.2$

Figure 6 : Fatigue life of rubber without stabilization (EDS14A) in air and sea water under non-relaxing conditions $(R=0.2)$

Figure 7 : Fatigue life of rubber in air and sea water under relaxing conditions $(R=0)$ for EDS14A material

Figure 8 : Effect of R-Ratio on the fatigue life of rubber in sea water for EDS14C 
Table 2 Formulations of the rubbers used in the study

\begin{tabular}{cccc}
\hline $\begin{array}{c}\text { Ingredients } \\
\text { (pphr) }\end{array}$ & EDS14A & EDS14B & EDS14C \\
\hline NR & 100 & 100 & 100 \\
Carbon black & 15 & 15 & 15 \\
Process oil & 1,5 & 1,5 & 1,5 \\
Zinc oxide & 5 & 5 & 5 \\
Stearic acid & 2 & 2 & 2 \\
Accelerator & 0,6 & 0,6 & 0,6 \\
Sulfur & 2,5 & 2,5 & 2,5 \\
Antioxidant & & $\mathbf{1}$ & $\mathbf{2}$ \\
$\mathbf{2 2 4 6}$ & $\mathbf{0}$ & & \\
\hline
\end{tabular}

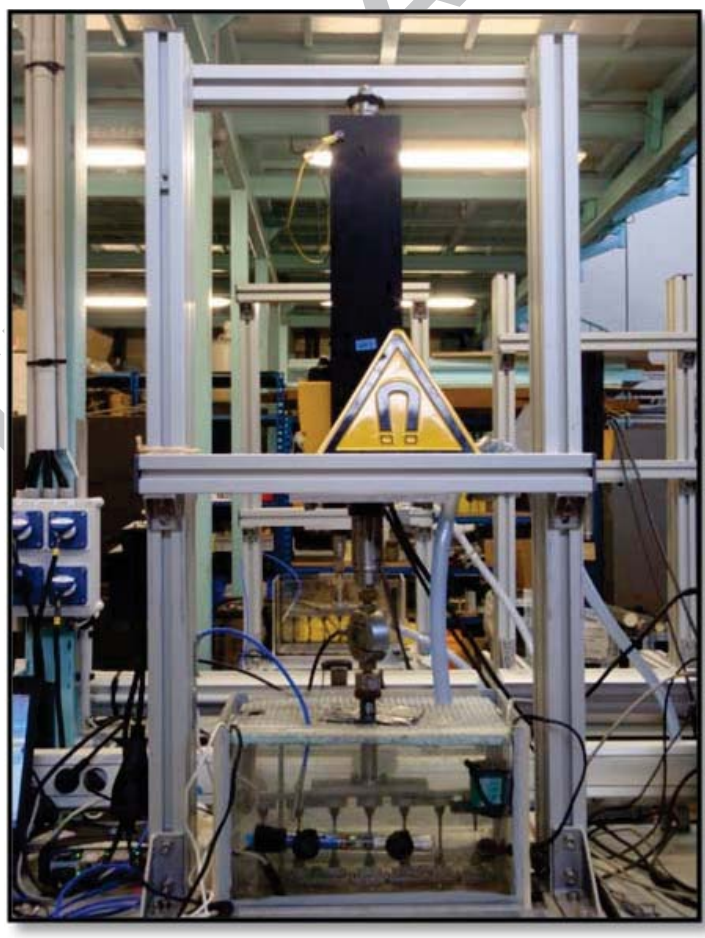

Figure 2 Testing machine developed at Ifremer 


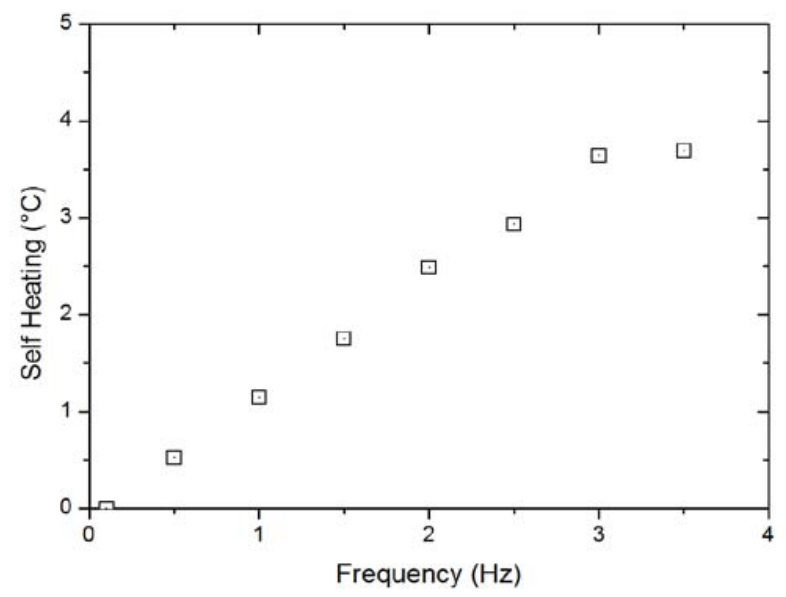

Figure 2 : Surface self-heating at EDS14 in air as function of frequency for a maximal strain of 2.5

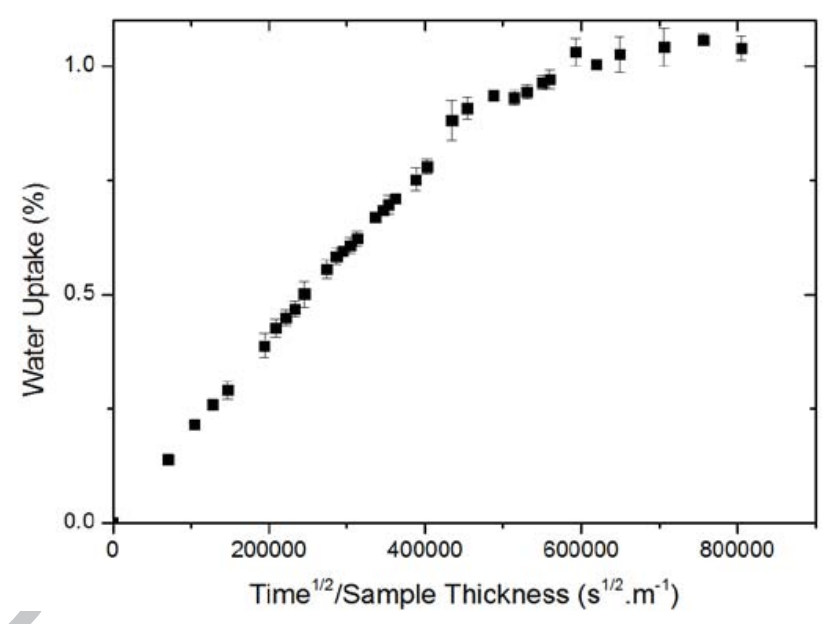

Figure 3: Water absorption in NR immersed in natural sea water at $25^{\circ} \mathrm{C}$ 


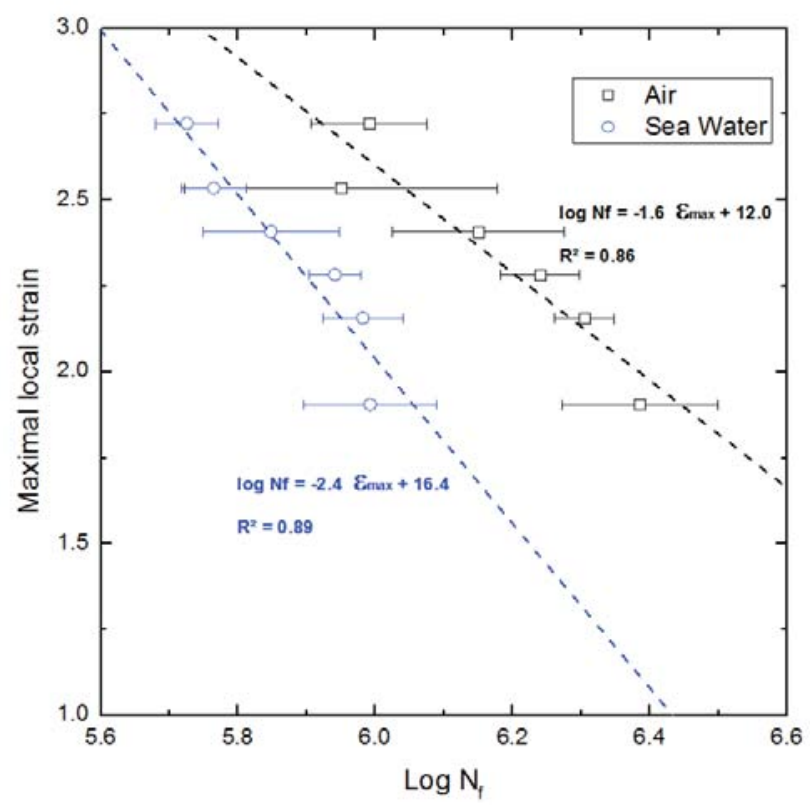

Figure 4 : Fatigue life of rubber in air and sea water under non-relaxing conditions $(R=0.2)$

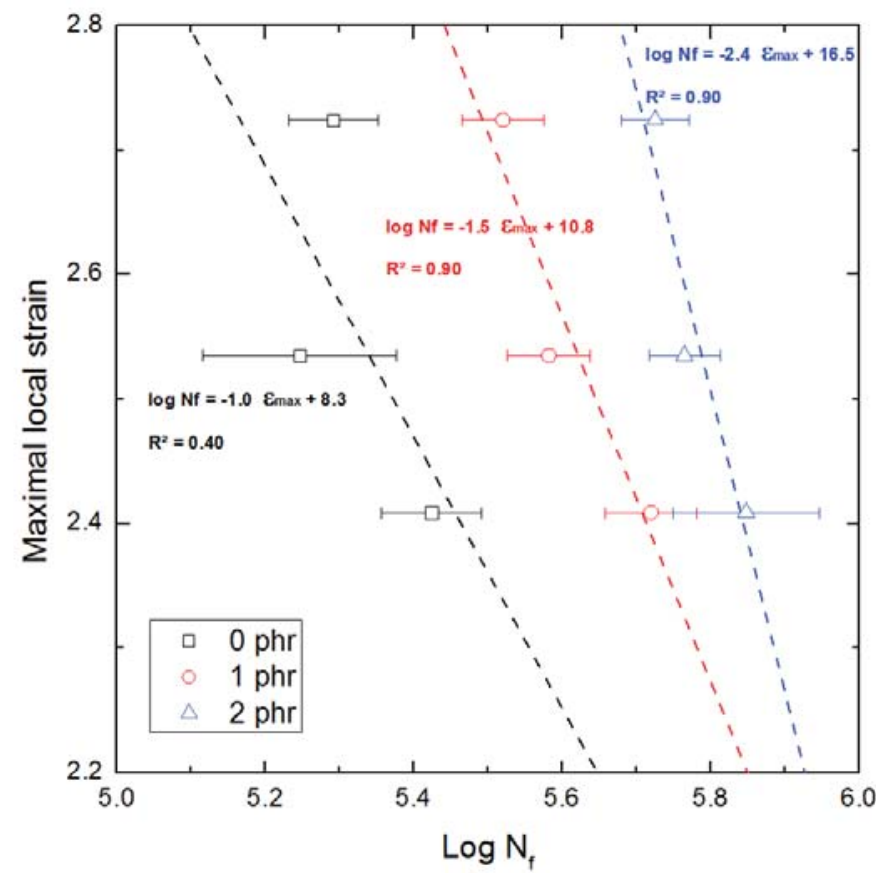

Figure 5 : Effect of antioxidants level on the fatigue life of natural rubber in sea water $R=0.2$ 


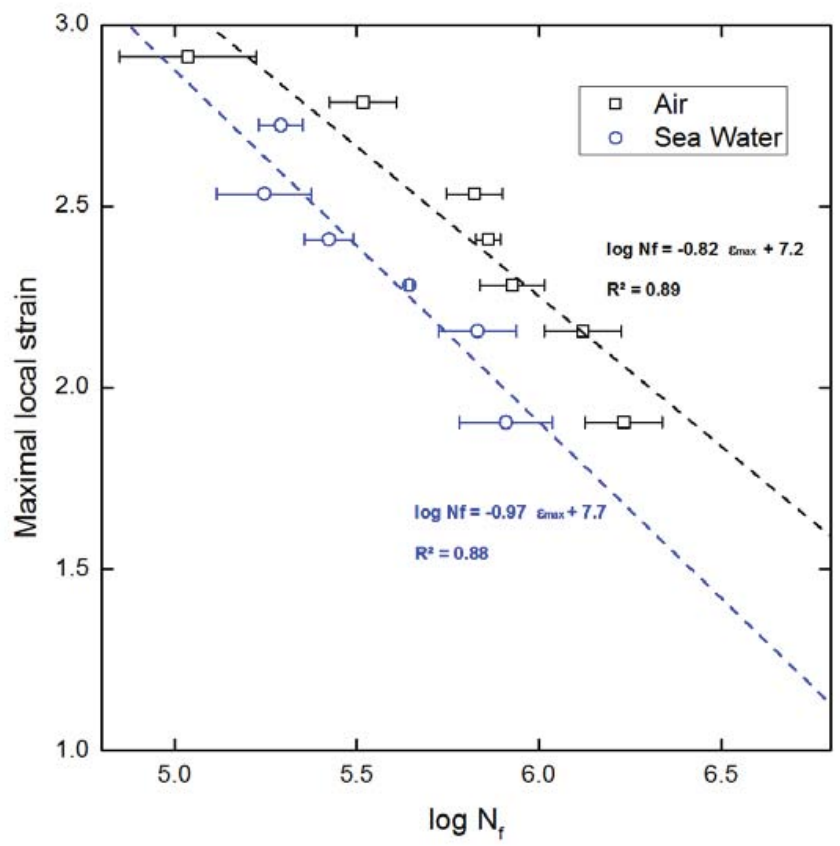

Figure 6 : Fatigue life of rubber without stabilization (EDS14A) in air and sea water under non-relaxing conditions $(R=0.2)$

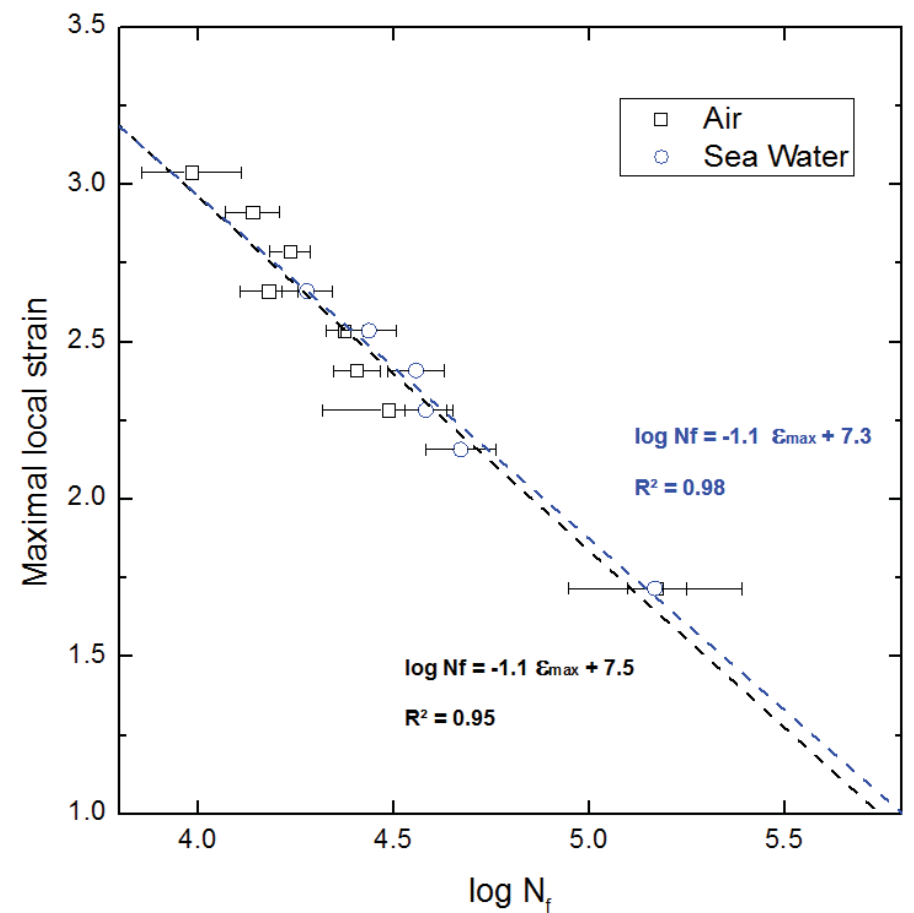

Figure 7 : Fatigue life of rubber in air and sea water under relaxing conditions $(R=0)$ for EDS14A material 


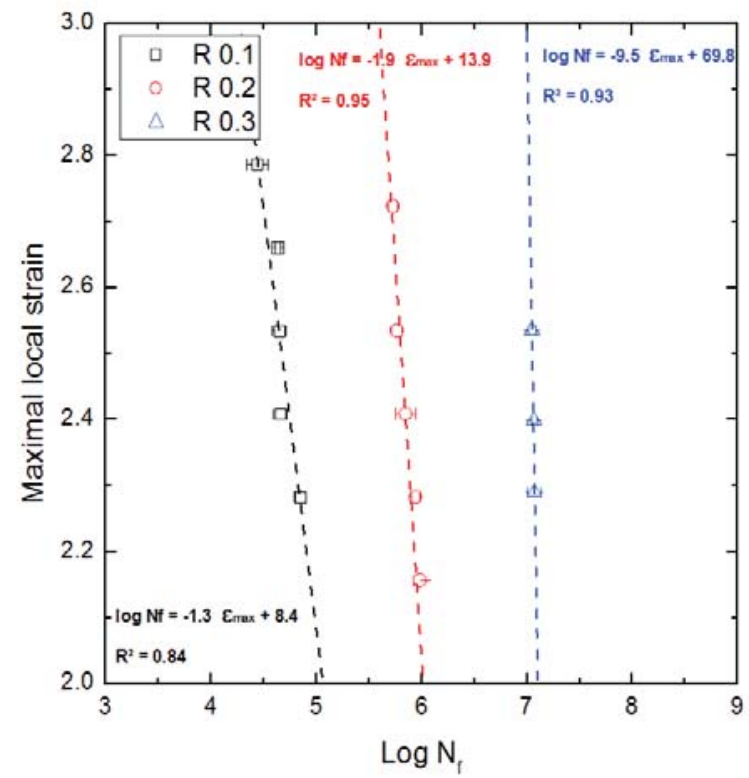

Figure 8 : Effect of R-Ratio on the fatigue life of rubber in sea water for EDS14 C 
Table 1 Formulations of the rubbers used in the study

\begin{tabular}{cccc}
\hline $\begin{array}{c}\text { Ingredients } \\
\text { (pphr) }\end{array}$ & EDS14A & EDS14B & EDS14C \\
\hline NR & 100 & 100 & 100 \\
Carbon black & 15 & 15 & 15 \\
Process oil & 1,5 & 1,5 & 1,5 \\
Zinc oxide & 5 & 5 & 5 \\
Stearic acid & 2 & 2 & 2 \\
Accelerator & 0,6 & 0,6 & 0,6 \\
Sulfur & 2,5 & 2,5 & 2,5 \\
Antioxidant & & & $\mathbf{2}$ \\
$\mathbf{2 2 4 6}$ & $\mathbf{0}$ & $\mathbf{1}$ & \\
\hline
\end{tabular}

